Article

\title{
Improved Buffering Capacity and Methane Production by Anaerobic Co-Digestion of Corn Stalk and Straw Depolymerization Wastewater
}

\author{
Fuli Yang, Wenzhe Li * (D), Mingchao Sun, Qiang Li, Mengyi Wang and Yong Sun \\ Department of Agriculture Biological Environment and Energy Engineering, School of Engineering, \\ Northeast Agriculture University, Harbin 150030, China; yangfuli408@163.com (F.Y.); \\ 13045138151@163.com (M.S.); lq4325356@163.com (Q.L.); wangmengyi66@163.com (M.W.); \\ sunyong@neau.edu.cn (Y.S.) \\ * Correspondence: liwenzhe95@163.com; Tel.: +86-451-5519-1985; Fax: +86-451-5519-0667
}

Received: 23 May 2018; Accepted: 27 June 2018; Published: 4 July 2018

\begin{abstract}
A new method has been developed to improve the buffer capacity and methane production of the anaerobic digestion of Corn Stalk (CS), in which both an anaerobic co-digestion of CS with Straw Depolymerization Wastewater (SDW) and a mono-digestion of CS at different substrate concentrations (25.9, 36.2 and $45.3 \mathrm{mg} / \mathrm{L})$ were investigated. Batch assays were conducted under thermophilic conditions for 70 days, which showed that an anaerobic co-digestion significantly increased the buffering capacity and methane production of the digestion process. The lag time for methane generation resulting from an anaerobic co-digestion of CS with SDW was 10 days, while the lag time for a mono-digestion of CS was 23 days. A maximum methane production of $214.81 \mathrm{~mL} / \mathrm{g}$-VS was obtained for the anaerobic co-digestion of CS with SDW when the substrate concentration was $36.2 \mathrm{~g} / \mathrm{L}$, which was around $13.54 \%$ higher than for mono-digestion of CS of $189.20 \mathrm{~mL} / \mathrm{g}$-VS. The removal rate for sulfate increased from $10.43 \%$ to $58.40 \%$ when the substrate concentration was increased from 25.9 to $45.3 \mathrm{mg} / \mathrm{L}$ for the anaerobic co-digestion of CS with SDW. Microbial communities were analyzed using 16S rDNA sequencing technology which showed that anaerobic co-digestion of CS and SDW promotes the growth of methanogens. The relative abundance of these methanogens (Euryarchaeota) for the anaerobic co-digestion of CS with SDW was increased significantly, being approximately $8.25 \%$ higher than that of a mono-digestion of CS, which was at a substrate concentration of $36.2 \mathrm{~g} / \mathrm{L}$. This means that the anaerobic co-digestion of CS and SDW is beneficial for improving buffer capacity and methane production from the digestion of CS, with higher organic matter and sulfate removal rates also being obtained.
\end{abstract}

Keywords: corn stalk; SDW; anaerobic co-digestion; buffer capacity; methane production

\section{Introduction}

The application of anaerobic digestion for the treatment of CS to produce methane-rich biogas is a popular method for achieving biomass energy conversion, which has both good economic and social benefits $[1,2]$. However, the complex structure of CS makes it difficult to degrade, often resulting in low conversion efficiencies when CS is used as a sole substrate for digestion [3,4]. In actual production, increasing the concentration of substration normally results in an increase in the volumetric biogas production rate. However, high substrate concentrations of CS can result in an increase in acidification of the anaerobic digestion system [5]. Previous studies have shown that initial Total Solid (TS) concentration generally does not exceed 6\% during the anaerobic digestion of CS [6]. This is due to the high carbon/nitrogen $(\mathrm{C} / \mathrm{N})$ content of $\mathrm{CS}$, which can result in large amounts of Volatile Fatty Acids 
(VFAs) accumulating in the fermenter, leading to unwanted acidification and a failure of the anaerobic digestion process. Therefore, it is difficult to increase the volumetric biogas production rate by simply increasing substrate concentration, because this would adversely affect the operational stability of the anaerobic digestion. Two methods have been developed to increase volumetric biogas production rates for the anaerobic digestion of CS. Firstly, anaerobic co-digestion of CS with a substrate containing high nitrogen content can be carried out; secondly, the inoculum used for digestion can be acclimated to tolerate higher substrate concentration levels. However, both methods increase the complexity and operating costs of anaerobic digestion systems [7].

The process of stalk depolymerization with dilute sulfuric acid (actual production conditions: $175^{\circ} \mathrm{C}, 0.8 \mathrm{MPa}, 120 \mathrm{~min}$ and $5 \%$ sulfate acid), usually encountered in the production chemicals (such as furfural and levulinic acid), generates large amounts of SDW (sulfate concentration of $1.94 \mathrm{~g} / \mathrm{L}$ ) that have the potential to pollute the environment when discharged incorrectly [8]. Although chemical treatment can be used to remove most of the sulfate content, these processes increase costs and can result in secondary pollution problems $[9,10]$. Currently, SDW treatment has become an economic bottleneck that restricts the application and development of stalk depolymerization processes. Studies have revealed that the addition of low concentrations of sulfate can promote degradation of propionic acid and improve methane fermentation performance during anaerobic digestion [11,12]. Furthermore, sulfides produced by sulfate reduction can also be used as an important source of sulfur for methanogen growth [13]. Sulfate-Reducing Bacteria (SRB) can operate over a wider $\mathrm{pH}$ range (5.5-9.0) than methanogens [14]; the latter activities are inhibited when $\mathrm{pH}$ is low $(<6)$ [15]. SRB can use VFAs as electron donors to reduce sulfates to sulfides, which result in a decrease in VFA concentration and an increase in $\mathrm{pH}$, which can promote the recovery of methanogenic processes [16]. $\mathrm{Du}$ Preez et al. [17] have reported that $1.042 \mathrm{~g}$ of $\mathrm{CaCO}_{3}$ is generated for every $1 \mathrm{~g}$ of sulfate reduced by SRB; thus, wastewater with a relatively high acidity could be treated with SRB. They also found acidic wastewater with a $\mathrm{pH}$ of 3.3 could be treated by SRB, becoming neutral. This means that sulfate can potentially act as a buffering agent for anaerobic digestion systems. Therefore, it is believed that an anaerobic co-digestion of CS and SDW can increase the buffering capacity and methane production at high substrate concentrations. However, little information is currently available on the anaerobic co-digestion of CS and SDW, because it was thought that the low $\mathrm{pH}$ of SDW would make it unsuitable for biogas production though anaerobic digestion [18].

The objective of this study was to find a new method to improve the buffering capacity and methane production through the anaerobic digestion of CS. Since the temperature of SDW was high [19], higher substrate concentrations are normally tolerated and greater biogas production produced when thermophilic anaerobic digestion were used [20]. Consequently, we compared the buffering capacity and methane production by anaerobic co-digestion of CS and SDW with that of mono-digestion of CS at different substrate concentrations under thermophilic conditions. These fermentations were carried out to make the most heat in SDW and to increase the efficiency of the anaerobic digestion.

\section{Results and Discussion}

\subsection{Methane Production}

Cumulative methane production profiles and fitted models for the anaerobic co-digestion of CS with SDW and the mono-digestion of CS at different substrate concentration of $25.9,36.2$, and $45.3 \mathrm{~g} / \mathrm{L}$ are shown in Figure 1. Methane production occurred over the first three days in all groups, mainly due to the activity of methanogens not being completely inhibited during the early stages of the digestion. 



Figure 1. Temporal profiles and mathematical fits for cumulative methane production for substrate concentrations of (a) $25.9 \mathrm{~g} / \mathrm{L}$; (b) $36.2 \mathrm{~g} / \mathrm{L}$; and (c) $45.3 \mathrm{~g} / \mathrm{L}$. Variation of Soluble Chemical Oxygen Demand (SCOD) and sulfate concentrations for anaerobic co-digestion of Corn Stalk (CS) and Straw Depolymerization Wastewater (SDW), for substrate concentrations of (d) $25.9 \mathrm{~g} / \mathrm{L}$; (e) $36.2 \mathrm{~g} / \mathrm{L}$; and (f) $45.3 \mathrm{~g} / \mathrm{L}$.

The results indicate that there was no significant difference in the cumulative methane production from the anaerobic co-digestion of CS with SDW and the mono-digestion of CS at a substrate concentration of $25.9 \mathrm{~g} / \mathrm{L}$ (Figure 1a). However, maximal methane production rates $\left(R_{m}\right)$ for the anaerobic co-digestion of CS with SDW $(32.57 \mathrm{~mL} /(\mathrm{g}$-VS-days)) were around $52 \%$ higher than for mono-digestion of CS (21.38 mL/(g-VS-days)) (Table 1). This trend was also identical for the other two substrate concentrations investigated, the increases in $R_{m}$ being caused by the ability of SRB to degrade propionic and butyrate acids to acetic acid in the presence of sulfate. The accumulation of acetic acid enhances methanogenic activity while also maintaining partial pressures of hydrogen at low levels [21,22]. The lag time for methane generation from the anaerobic co-digestion of CS and SDW at a substrate concentration of $36.2 \mathrm{~g} / \mathrm{L}$ was 10 days, whereas the corresponding lag time for the mono-digestion of CS $(36.2 \mathrm{~g} / \mathrm{L})$ was 23 days. The delay period for both groups is caused by an increase in substrate concentration that results in VFA accumulation, which can lead to the methanogenesis pathways being greatly inhibited. The lag time for the anaerobic co-digestion of CS with SDW was much less than the lag time for mono-digestion of CS, primarily due to the activity of methanogens being inhibited when $\mathrm{pH}$ is low. In contrast, SRBs were able to use VFAs as electron donors to reduce sulfates to sulfides, thus reducing VFA concentration and increasing $\mathrm{pH}$ to promote recovery of methanogenic processes [14]. This hypothesis was supported by the observation of decreased sulfate 
and VFA concentration during this period. A substrate concentration of $36.2 \mathrm{~g} / \mathrm{L}$ gave maximum methane production for the anaerobic co-digestion of CS and SDW of $214.81 \mathrm{~mL} / \mathrm{g}$-VS, which was around $13.54 \%$ higher than the $189.20 \mathrm{~mL} / \mathrm{g}$-VS obtained for mono-digestion of CS. When substrate concentration was $45.3 \mathrm{~g} / \mathrm{L}$, the methanogenic process being inhibited significantly during the initial phase of the anaerobic digestion because of acidification. The lag phase times for methane generation from the anaerobic co-digestion of CS with SDW and the mono-digestion of CS were 27 days and 35 days (respectively), and cumulative methane production was only 171.62 and $139.18 \mathrm{~mL} / \mathrm{g}$-VS, respectively. Increased methane production may be due to sulfide produced by sulfate reduction, itself being used as an important sulfur source to promote methanogen growth [23]. Therefore, the anaerobic co-digestion of CS and SDW can significantly shorten the lag period of methane generation and increase the buffer capacity of the digestion system, particularly at high substrate concentrations. The cumulative methane production for the control group, which only contained anaerobic sludge and $25 \mathrm{~mL}$ of SDW, was only $102.61 \mathrm{~mL} / \mathrm{g}$-VS, the low methane production being related to the low $\mathrm{C} / \mathrm{S}$ ratio of SDW. Li et al. have previously shown that the use of a benzoate as substrate, with a $\mathrm{C} / \mathrm{S}$ ratio $<0.75$, resulted in $87 \%$ of the electrons being used by SRB, with no methane being detected in its biogas [24].

Table 1. Kinetic parameters from mathematically fitted profiles obtained for methane production.

\begin{tabular}{|c|c|c|c|c|c|}
\hline \multirow{2}{*}{$\begin{array}{c}\text { Substrate } \\
\text { Concentration }\end{array}$} & & \multicolumn{4}{|c|}{ Methane Production } \\
\hline & & $P_{\infty}{ }^{a}$ & $R_{m}{ }^{b}$ & $\lambda^{\mathrm{c}}$ & $R^{2}$ \\
\hline \multirow{2}{*}{$\begin{array}{c}25.9 \mathrm{~g} / \mathrm{L} \\
\text { (Figure 1a) }\end{array}$} & $\begin{array}{l}\text { co-digestion of } \\
\text { CS with SDW }\end{array}$ & $181.18 \pm 3.73$ & $32.57 \pm 0.92$ & $0.69 \pm 0.02$ & $0.9908 \pm 0.0034$ \\
\hline & $\begin{array}{c}\text { mono-digestion } \\
\text { of CS }\end{array}$ & $183.97 \pm 4.32$ & $21.38 \pm 1.61$ & $0.21 \pm 0.00$ & $0.9883 \pm 0.0011$ \\
\hline \multirow{2}{*}{$\begin{array}{c}36.2 \mathrm{~g} / \mathrm{L} \\
\text { (Figure 1b) }\end{array}$} & $\begin{array}{l}\text { co-digestion of } \\
\text { CS with SDW }\end{array}$ & $214.81 \pm 1.89$ & $10.86 \pm 0.92$ & $5.23 \pm 0.06$ & $0.9750 \pm 0.0023$ \\
\hline & $\begin{array}{c}\text { mono-digestion } \\
\text { of CS }\end{array}$ & $189.20 \pm 3.69$ & $6.21 \pm 0.51$ & $23.82 \pm 0.99$ & $0.9465 \pm 0.0072$ \\
\hline \multirow{2}{*}{$\begin{array}{c}45.9 \mathrm{~g} / \mathrm{L} \\
\text { (Figure 1c) }\end{array}$} & $\begin{array}{l}\text { co-digestion of } \\
\text { CS with SDW }\end{array}$ & $171.62 \pm 1.43$ & $4.66 \pm 0.02$ & $27.32 \pm 1.78$ & $0.9285 \pm 0.0102$ \\
\hline & $\begin{array}{c}\text { mono-digestion } \\
\text { of CS }\end{array}$ & $139.18 \pm 0.68$ & $5.61 \pm 0.42$ & $35.69 \pm 3.62$ & $0.9061 \pm 0.0003$ \\
\hline
\end{tabular}

Notes: ${ }^{\mathrm{a}} \mathrm{L} / \mathrm{kg}-\mathrm{VS} ;{ }^{\mathrm{b}} \mathrm{L} / \mathrm{kg}-\mathrm{VS} /$ day; ${ }^{\mathrm{c}}$ day; Values are expressed as means with \pm standard deviations $(n=3)$.

\subsection{Variation of SCOD and Sulfate Concentrations}

Methanogens and Sulfur-Oxidizing Bacteria (SOB) can compete with SRB for substrate during the anaerobic digestion of CS and SDW. Methanogens with SRB compete for acetic acid and hydrogen [25], and microbial competition is determined by the characteristic of inoculum and sulfate concentrations. $\mathrm{SOB}$ and $\mathrm{SRB}$ compete for carbon sources through a symbiotic relationship, presenting a phenomenon of counter-balance [26].

Variations in sulfate concentrations for the anaerobic co-digestion of CS with SDW under substrate concentrations of 25.9, 36.2, and 45.3 g/L are shown in Figure $1 \mathrm{~d}-\mathrm{f}$. Sulfate concentration increased over the first 4 days with a substrate concentration of $25.9 \mathrm{~g} / \mathrm{L}$, which was caused by the presence of nitrates in the initial fermentation broth. This resulted in SOB utilizing nitrate as an electron acceptor to oxidize sulfide to sulfate, which lead to an overall increase in sulfate concentration [27]:

$$
\mathrm{S}^{2-}+1.6 \mathrm{NO}_{3}^{-}+1.6 \mathrm{H}^{+} \rightarrow \mathrm{SO}_{4}^{2-}+0.8 \mathrm{~N}_{2}+0.8 \mathrm{H}_{2} \mathrm{O}
$$

Sulfide oxidation processes normally predominate over sulfate reduction processes, with nitrite produced from nitrate reduction acting as a strong inhibitor of SRB. This inhibition is due to a nitrite reductase in the periplasm of SRB accepting electrons from redox proteins (QmoABC complex 
and DsrMKJOP complexes) of the SRB electron transport pathway to reduce nitrite to ammonia, which then results in a decrease in the activities of proteins associated with the sulfate respiratory pathway [28]. Inoculum was acclimatized using cattle manure for 40 days prior to use, in order to ensure that methanogens would be able to metabolize acetic acid; hydrogen predominated, which also resulted in the inhibition of sulfate reduction during the initial incubation period. After 4 days, the concentration of sulfate decreased rapidly, falling to $116.49 \mathrm{mg} / \mathrm{L}$ on the 8 th day due to consumption of sulfide and Soluble Chemical Oxygen Demand (SCOD) as well as increase of sulfate concentration. Negligible variations in sulfate concentrations were observed after the eighth day of incubation.

The concentration of sulfate increased and reached peak values on days 2 and 4 when the substrate concentrations were 36.2 and $45.3 \mathrm{~g} / \mathrm{L}$, respectively. Following this, a rapid decline in sulfate concentration was observed, primarily due to system acidification being caused by high substrate concentrations inhibiting the methanogenesis process, while SRB capable of using VFAs as a feedstock to grow that also results in reduction of sulfate to sulfide. The sulfate concentrations dropping to 67.77 and $42.90 \mathrm{mg} / \mathrm{L}$ on days 8 and 28 for substrate concentrations of 36.2 and $45.3 \mathrm{~g} / \mathrm{L}$, respectively. After 8 days and 28 days, low VFA levels can relieve the suppression effect of VFAs on methanogen activity when substrate concentration of 36.2 and $45.3 \mathrm{~g} / \mathrm{L}$ (Figure 2). Methanogens can outcompete SRB for acetic acid and hydrogen, resulting in SRB activity decreasing during this period. Increasing sulfide concentration and decreasing SRB activity promotes SOB activity, which results in a transient increase in sulfate concentration when methane generation is to be recovered. After both 14 and 44 days, the sulfate concentration for substrate concentrations of 36.2 and $45.3 \mathrm{~g} / \mathrm{L}$ were decreased, resulting in $38.88 \%$ and $58.40 \%$ reduction in sulfate concentration at the end of each experiment, respectively. Apart from this, the results also show that sulfate removal mainly occurs during the acidification stage of the anaerobic digestion, and the sulfate concentration first increasing, and then decreasing, with the overall variation in sulfate concentration not being significant during the methanogenic process. Therefore, the anaerobic co-digestion of CS and SDW at high substrate concentrations not only improves buffering capacity and volumetric biogas production rates, but also results in high removal rates of sulfate. Meanwhile, mutual transformation of sulfate and sulfide can promote the removal of organic matter (Figure 3) and convert sulfate into elemental sulfur to enable complete desulfurization of wastewater.

The variation of SCOD concentration during anaerobic co-digestion CS with SDW are shown in Figure $1 \mathrm{~d}-\mathrm{f}$, which indicates that SCOD concentrations play a decisive role in methane production. When the SCOD concentration is $>8 \mathrm{~g} / \mathrm{L}$, acidification occurs in anaerobic digestion systems and methanogenesis are inhibited, while SRB predominates in carbon source utilization. Methanogen governs VFA consumption (with concomitant increases in methane production), leading to a rapid decline in SCOD concentrations for SCOD concentration between $8 \mathrm{~g} / \mathrm{L}$ and $4 \mathrm{~g} / \mathrm{L}$. When SCOD concentration were between 1 and $4 \mathrm{~g} / \mathrm{L}$, methanogens and SRB could coexist and compete for acetic acid and hydrogen in the anaerobic digestion reactor. However, when SCOD levels were $<1 \mathrm{~g} / \mathrm{L}$, low organic matter concentration levels resulted in methane production and sulfate reduction being suppressed. In this study, sulfide oxidation always occurs in the early stage of the methane production, which is not dependent on the SCOD concentration of the fermentation broth. These results are consistent with the results of $16 \mathrm{~S}$ ribosomal Deoxyribonucleic Acid (rDNA) sequencing studies, which revealed SOB (Sulfuricurvum) is an autotrophic bacterium, whose activities are primarily determined by sulfide concentration levels.

\subsection{Variation in VFA Concentration and $p H$}

Variation in VFA concentrations and $\mathrm{pH}$ for the anaerobic co-digestion of CS with SDW and the mono-digestion of CS for substrate concentrations of 25.9, 36.2 and $45.3 \mathrm{~g} / \mathrm{L}$ are shown in Figure 2. These results show that the anaerobic co-digestion of CS and SDW can promote the degradation of VFAs regardless of substrate concentration, because SRB growth on VFAs is promoted by the presence of sulfate. When there were high substrate concentrations of $36.2 \mathrm{~g} / \mathrm{L}$, VFA concentration dropped to 
approximately $10 \mathrm{~g} / \mathrm{L}$ on the 8th day; however, VFAs concentrations for mono-digestion of CS fell to $12 \mathrm{~g} / \mathrm{L}$ after 28 days. It is well-known that high substrate concentration levels can result in the acidification of anaerobic digestion systems. The anaerobic co-digestion of CS with SDW for substrate concentration of $45.3 \mathrm{~g} / \mathrm{L}$ resulted in VFA concentrations decreasing to $10 \mathrm{~g} / \mathrm{L}$ at the 28th day, but this level was still significantly better than what was achieved for the mono-digestion of CS, namely taking 44 days to reach the same level. Therefore, it can be concluded that the anaerobic co-digestion of CS and SDW at substrate concentrations of between $25.9 \mathrm{~g} / \mathrm{L}$ and $36.2 \mathrm{~g} / \mathrm{L}$ can significantly promote VFA degradation and increase the buffering capacity of the anaerobic digestion system. In addition, levels of methane production and VFAs concentrations indicate that the anaerobic digestion system can restore biogas production when the total VFA concentrations (mainly acetic acid, propionate acid, and butyric acid) is less than $10 \mathrm{~g} / \mathrm{L}$. In addition, the Volatile Solid (VS) degradation in anaerobic co-digestion of CS with SDW were higher than that of mono-digestion of CS under a different substrate concentration, especially when the substrate concentration of $36.2 \mathrm{~g} / \mathrm{L}$-compared with the degradation of the former-was about $72 \%$ higher than that of the latter (Figure 3).

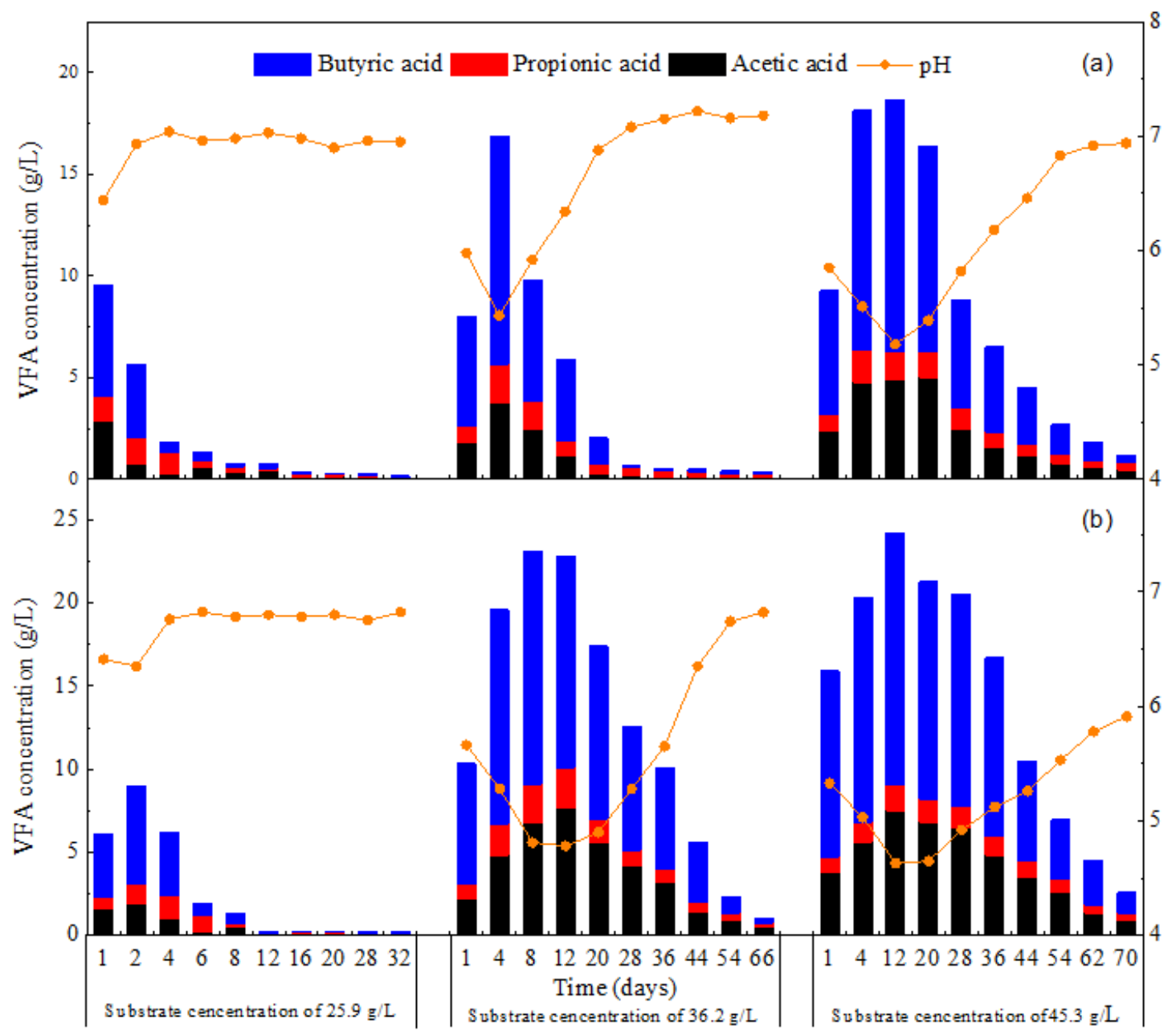

Figure 2. Variation in Volatile Fatty Acids (VFAs) concentrations and $\mathrm{pH}$ for anaerobic co-digestion of CS and SDW (a) and mono-digestion of CS (b) at substrate concentrations of 25.9, 36.2 and $45.3 \mathrm{~g} / \mathrm{L}$. 




Figure 3. VS degradation of anaerobic co-digestion of CS and SDW and mono-digestion of CS at substrate concentrations of $25.9,36.2$, and $45.3 \mathrm{~g} / \mathrm{L}$.

\subsection{Analysis of Microbial Communities}

The microbial community structure present in fermentation broths determines the performance of the anaerobic digestion system and the microbial population distribution of the anaerobic digestion reactor $[29,30]$. Consequently, the effect of SDW on the overall structure of the bacterial community during anaerobic co-digestion of CS with SDW and mono-digestion of CS, were analyzed at a substrate concentration of $36.2 \mathrm{~g} / \mathrm{L}$ using $16 \mathrm{~S}$ rDNA sequencing at the end of digestion.

Firmicutes, Synergistetes, Bacteroidetes, Euryarchaeota, and Proteobacteria were the dominant groups in the fermentation broths after 66 days of anaerobic co-digestion of CS with SDW and mono-digestion of CS (Figure 4). Firmicutes is a typical syntrophic bacteria strain that can decompose VFAs to produce hydrogen, that can then be reduced by hydrogenolytic methanogens to produce methane [31]. Synergistetes is a recently recognized genus of anaerobic bacteria that is associated with methane production from acetic acid [32]. Therefore, increases in the relative abundance of Synergistetes and Firmicutes in fermentation broths for the anaerobic co-digestion of CS and SDW can effectively promote hydrolysis of organic matter to increase methane production [33]. Bacteroidetes is a type of proteolytic bacteria that is responsible for protein degradation [34]; its relative abundance for the anaerobic co-digestion of CS and SDW is lower than for the mono-digestion of CS. However, the protein content of CS is low, the decreased relative abundance of Bacteroidetes not adversely affecting CS hydrolysis. Analyses revealed that almost all the Euryarchaeota found in the 16S rDNA sequencing studies were methanogens [35]. The relative abundance of Euryarchaeota (9.84\%) in the anaerobic co-digestion of CS and SDW was found to be $8.25 \%$ higher than in mono-digestion using CS (9.09\%). This indicates that the anaerobic co-digestion of CS and SDW can significantly promote the growth of methanogens, the main methanogens are Methanosarcina, Methanobacterium, and Methanosaeta all being capable of degrading VFAs to hydrogen for methane production [36,37]. The relative abundance of SOB (Sulfuricuroum) and SRB (Desulfovibrio) in Proteobacteria [38,39] for the anaerobic co-digestion of CS and SDW were higher than those for mono-digestion of CS (data not shown). Both SOB and SRB were able to improve the mutual transformation of sulfate and sulfide, with results increasing the removal rate of organic matter [40]. 


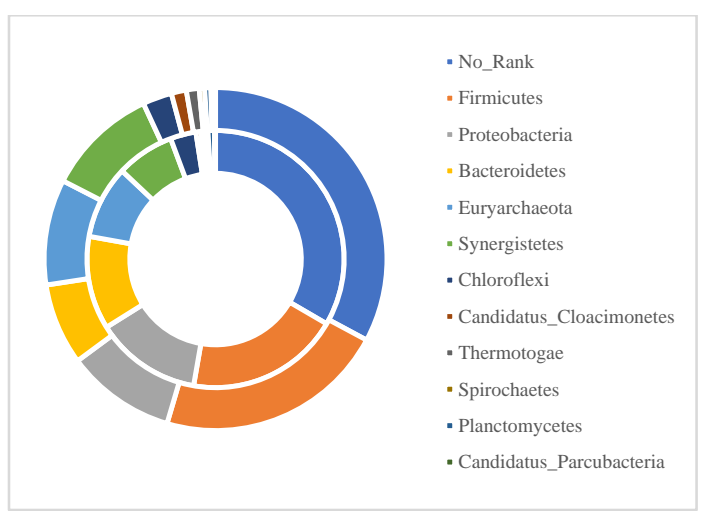

(a)

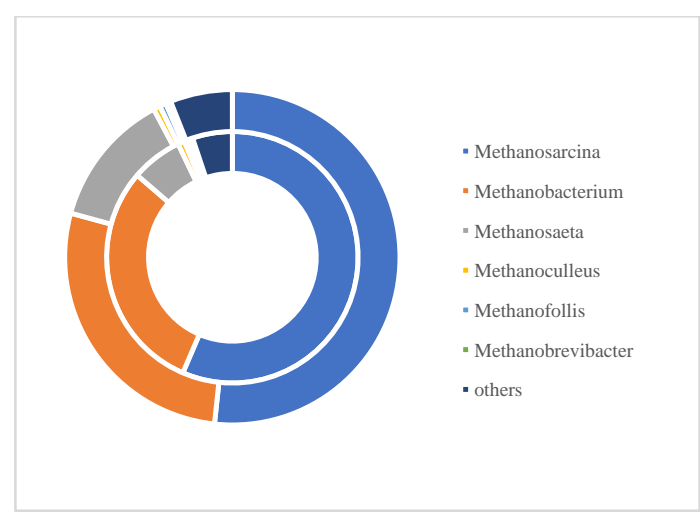

(b)

Figure 4. Phylum-level bacterial population distribution and genus-level archaeal population distribution for anaerobic co-digestion of CS and SDW (outer layer) and mono-digestion of CS (inner layer) at substrate concentration of $36.2 \mathrm{~g} / \mathrm{L}$. (a) Phylum-level bacterial population distribution; (b) genus-level archaeal population distribution.

\section{Materials and Methods}

\subsection{Feedstocks and Inoculum}

The SDW investigated in this study was obtained from the pilot plant from the Liaoning Institute of Energy Conversion in Yingkou City. The wastewater sample was filtered through a $0.45 \mu \mathrm{m}$ polyethersulfone membrane before analysis. The $\mathrm{pH}$ of SDW was adjusted to approximately 5 prior to use. The corn stalk used in this study was obtained from a farm at Northeast Agriculture University in Harbin City and was dried prior to use. The dried corn stalk was crushed in a shredder. The crushed corn stalk diameter was approximately $2 \mathrm{~cm}$. The anaerobic sludge used as an inoculum was collected from an anaerobic digester (working volume: $2000 \mathrm{~mL}$ ) which digested cattle manure at $35^{\circ} \mathrm{C}$ for 40 days. The characteristics of the SDW, corn stalk, and inoculums used in this study are shown in Table 2.

Table 2. Characteristic of the SDW, corn stalk and inoculum.

\begin{tabular}{cccc}
\hline Parameters & SDW & Corn Stalk & Inoculum \\
\hline TS (\%) & $4.87 \pm 0.02$ & $94.07 \pm 0.50$ & $4.46 \pm 0.02$ \\
VS (\%) & $1.66 \pm 0.01$ & $88.95 \pm 0.91$ & $3.12 \pm 0.01$ \\
pH & $2.25 \pm 0.01$ & - & $6.94 \pm 0.01$ \\
SCOD (g/L) & $12.15 \pm 0.77$ & - & $3.30 \pm 0.21$ \\
Sulphate (g/L) & $1.94 \pm 0.10$ & - & $0.01 \pm 0.00$ \\
Nitrate (mg/L) & $3.02 \pm 0.02$ & - & $1.534 \pm 0.02$ \\
Methanol (g/L) & $0.124 \pm 0.00$ & - & - \\
Acetic acid (g/L) & $1.83 \pm 0.02$ & - & - \\
Propionic acid (g/L) & $0.14 \pm 0.00$ & - & - \\
Butyric acid (g/L) & $0.38 \pm 0.00$ & - & - \\
C (\%) & $10.48 \pm 0.07$ & $38.63 \pm 0.02$ & $30.04 \pm 0.04$ \\
N (\%) & $1.65 \pm 0.00$ & $0.78 \pm 0.03$ & $2.55 \pm 0.10$ \\
Cellulose (\%) & - & $34.10 \pm 0.11$ & $11.59 \pm 0.06$ \\
Hemi-cellulose (\%) & - & $28.36 \pm 0.08$ & $24.99 \pm 0.00$ \\
Lignin (\%) & - & $5.57 \pm 0.03$ & $25.04 \pm 0.01$ \\
\hline
\end{tabular}

$\%$ of dry matter weight; -: not determined. Values are expressed as means \pm standard deviations $(n=3)$.

\subsection{Experimental Setup and Procedure}

The batch reactors consisted of $1000 \mathrm{~mL}$ glass flasks. The experiments were divided into 2 groups: experimental group A, the mono-digestion of corn stalk; and experimental group B, 
the anaerobic co-digestion of corn stalk and SDW. For experimental group A, to obtain different substrate concentrations of 25.9, 36.2, and $45.3 \mathrm{~g} / \mathrm{L}$ (based on total solid) in the fermentation broths, $580 \mathrm{~mL}$ of anaerobic sludge and 17.5, 24.5, and $30.5 \mathrm{~g}$ of corn stalk were added, respectively. In experimental group B, $580 \mathrm{~mL}$ of anaerobic sludge and 17.5, 24.5, and $30.5 \mathrm{~g}$ of corn stalk were added, followed by the addition of $25 \mathrm{~mL}$ of SDW to obtain sulfate concentrations of $85.5 \mathrm{mg} / \mathrm{L}$ in the fermentation broths (Pre-experimental results show that methanogenic process are not be affected by the sulfate concentration of $89 \mathrm{mg} / \mathrm{L}$ ). In control group, $580 \mathrm{~mL}$ of anaerobic sludge and $25 \mathrm{~mL}$ of SDW were added to investigate the effect of SCOD in SDW on the anaerobic digestion. Some distilled water was added (if necessary) to ensure that the quantities of fermentation broths in the control and experimental groups remained consistent. The batch experiments were performed at a thermophilic level of $55 \pm 1^{\circ} \mathrm{C}$. All reactors were warmed in a Digital Biochemical incubator (Memmert IPP260, Memmert GmbH + Co. KG, Schwabach, Germany). Each group was tested in six flasks, including three for the gaseous phase (including biogas volume and biogas composition), and three for the liquid phase (including the SCOD, sulfate, $\mathrm{pH}$, and VFAs) [41]. Gas and liquid samples of anaerobic co-digestion of corn stalk with SDW and mono-digestion of corn stalk were analysed every day and then every 2 days after the initial incubation time, and the analysis interval was gradually increased over time. The Total Solid (TS) and VS in the fermentation broths were analysed at the end of anaerobic co-digestion. The reactors were monitored for 70 days.

\subsection{Analytical Methods}

TS, VS and $\mathrm{pH}$ were measured according to the Standard Methods for the Examination of Water and Wastewater (APHA, 2005). SCOD were analysed using the rapid-digestion method (HH-6, Jiangsu Jiangfen Electroanalytical Instrument Co., Ltd., Taizhou, China). Biogas volumes were measured via a water displacement method. The biogas composition (hydrogen, methane, nitrogen, and carbon dioxide) was determined via gas chromatography (GC-6890N, Agilent Inc., Santa Clara, CA, USA) using a Thermal Conductivity Detector (TCD). VFAs (acetic, propionic, butyric and total VFAs) and solvents (methanol and ethanol) were also analysed via gas chromatography (GC-6890N, Agilent Inc., Santa Clara, CA, USA) using a Flame Ionization Detector (FID) and a capillary column (Agilent 1909/N-133 HP-INNOWAX Polyethylene Glycol). The temperatures of injector port, oven, and detector were to $220^{\circ} \mathrm{C}$ and $250{ }^{\circ} \mathrm{C}$, respectively. The initial temperature of the oven was $60^{\circ} \mathrm{C}$, then increased to $140^{\circ} \mathrm{C}$ at a rate of $15^{\circ} \mathrm{C} / \mathrm{min}$ and maintained for $2 \mathrm{~min}$. The carrier gas was argon with a flow rate of $30 \mathrm{~mL}$ min and constant pressure of $187 \mathrm{kPa}$; the gas measurement time was $7.33 \mathrm{~min}$. The sulfate and nitrate concentrations were determined with a Skalar flow analyser (SA-5000, Skalar Analytical B.V., Breda, The Netherlands). Carbon and nitrogen levels were determined using an elemental analyser (EA 3000, LEEMAN Technologies Co., Ltd., Beijing, China). All measurements were conducted in triplicate, and the averaged data are presented. The batch experiment data were analysed using Origin 8.0 (OriginLab Corporation, Northampton, MA, USA).

The microbial community was analysed using $16 \mathrm{~S}$ rDNA sequencing technology. The fermentation broths were collected from the reactor (anaerobic co-digestion of corn stalk with SDW and mono-digestion of corn stalk with substrate concentration of $36.2 \mathrm{~g} / \mathrm{L}$ ) at the end of the experiment for DNA extraction. A universal primer set (515F/806R, 5'-GTGCCAGCMGCCGCGGTAA-3' $/ 5^{\prime}$ GGACTACHVGGGTWTCTAAT-3') was used to amplify the V4 region of the $16 \mathrm{~S}$ rDNA gene. To minimize variations, Polymerase Chain Reaction (PCR) assays were performed in triplicate for each sample. The thermal cycling consisted of one initial denaturation cycle at $94{ }^{\circ} \mathrm{C}$ for $120 \mathrm{~s} ; 25$ cycles of denaturation at $94{ }^{\circ} \mathrm{C}$ for $20 \mathrm{~s}$, annealing at $55^{\circ} \mathrm{C}$ for $30 \mathrm{~s}$ and extension at $72{ }^{\circ} \mathrm{C}$ for $60 \mathrm{~s}$; and a final extension at $72{ }^{\circ} \mathrm{C}$ for $10 \mathrm{~min}$. The sample was then stored at $4{ }^{\circ} \mathrm{C}$. The PCR products were examined via agarose gel electrophoresis and quantified using a NanoDrop 2000 spectrophotometer (Thermo Scientific, Waltham, MA, USA). Then, $16 \mathrm{~S}$ rDNA sequencing was performed on an Illumina MiSeq Benchtop Sequencer by the Centre for Genetic \& Genomic Analysis, Genesky Biotechnologies, Inc. (Shanghai, China). 
The modified Gompertz equations has a wide range of applications in the field of methane production [42], it could be presented as Equation (2):

$$
P(t)=P_{\infty} \times \exp \left\{-\exp \left[\frac{R_{m} \times e}{P_{\infty}} \cdot(\lambda-t)+1\right]\right\}
$$

where $P(t)$ is the accumulation methane production $(\mathrm{mL})$ at time $t$ (day), $P_{\infty}$ is the cumulative methane production potential $(\mathrm{mL}), R_{m}$ is the maximal methane production rate $(\mathrm{mL} / \mathrm{d}), \lambda$ is the duration of lag phase (day) while $t$ is the time over the fermentation period and $e$ is equivalent to 2.718282 . In this experiment, the modified Gompertz equations was used to simulate cumulative methane production from an anaerobic co-digestion of corn stalk with SDW, as well as a mono-digestion of corn stalk under different substrate concentration by Origin 8.0 version.

\section{Conclusions}

(1) Anaerobic co-digestion of CS and SDW can significantly increase the buffering capacity and methane production. The lag time for methane generation from the anaerobic co-digestion of CS and SDW was 10 days, however, the lag time for mono-digestion of CS was 23 days for a substrate concentration of $36.2 \mathrm{~g} / \mathrm{L}$. Maximum methane production from anaerobic co-digestion of CS and SDW of $214.81 \mathrm{~mL} / \mathrm{g}$-VS was about $7.76 \%$ higher than for mono-digestion of CS which gave a value of $199.34 \mathrm{~mL} / \mathrm{g}$-VS. Increasing the substrate concentration to $45.3 \mathrm{~g} / \mathrm{L}$ resulted in methanogenic processes being significantly inhibited during the initial anaerobic digestion stage. However, the fermentation performance and buffering capacity observed for anaerobic co-digestion of CS and SDW were significantly better than levels obtained for mono-digestion of CS.

(2) The removal rate of sulfate increased from $10.43 \%$ to $58.40 \%$ when the substrate concentration was increased from 25.9 to $45.3 \mathrm{mg} / \mathrm{L}$ for anaerobic co-digestion of CS and SDW.

(3) $16 \mathrm{~S}$ rDNA sequencing results showed that anaerobic co-digestion of CS and SDW promoted growth of methanogens, the relative abundance of Euryarchaeota (mainly Methanosarcina, Methanobacterium, and Methanosaeta) for anaerobic co-digestion of CS and SDW being 9.84\%, which was $8.25 \%$ higher than the $9.09 \%$ of Euryarchaeota present in mono-digestion of CS. SOB and SRB could both improve mutual transformation of sulfate and sulfide, as well as increase the overall removal rate of organic matter.

Author Contributions: F.Y. and W.L. conceived and designed the experiments; F.Y., M.S., Q.L., and M.W. performed the experiments; F.Y. analyzed the data; Y.S. contributed reagents/materials/analysis tools; F.Y. wrote the paper.

Acknowledgments: This research was funded by the Central Specialized Fund for the Development of Local Science and Technology grant number (No. ZY17C05), Harbin special fund for scientific and technological innovation talents research project (2016RAXXJ009), and the Youth Science Foundation of Heilongjiang Province (QC2016033).

Conflicts of Interest: The authors declare no conflict of interest.

\section{References}

1. Guo, P.; Mochidzuki, K.; Cheng, W.; Zhou, M.; Gao, H.; Zheng, D. Effects of different pretreatment strategies on corn stalk acidogenic fermentation using a microbial consortium. Bioresour. Technol. 2011, 102, 7526-7531. [CrossRef] [PubMed]

2. Liu, S.; Wu, S.B.; Zhang, W.Q.; Pang, C.; Deng, Y.; Dong, R.J. Effect of White-rot Fungi Pretreatment on Methane Production from Anaerobic Digestion of Corn Stover. Trans. Chin. Soc. Agric. Mach. 2013, 44, 124-129.

3. Zhu, J.Y.; Wan, C.X.; Li, Y. Enhanced solid-state anaerobic digestion of corn stover by alkaline pretreatment. Bioresour. Technol. 2010, 101, 7523-7528. [CrossRef] [PubMed] 
4. Yu, J.; Zhao, Y.; Liu, B.; Zhao, Y.; Wu, J.; Yuan, X. Accelerated acidification by inoculation with a microbial consortia in a complex open environment. Bioresour. Technol. 2016, 216, 294-301. [CrossRef] [PubMed]

5. Zhong, M.; Duan, N.; Lin, C.; Zhang, D.; Liang, S.; Sun, H. Effects of organic loading rate and additive on corn stalk anaerobic digestion. J. Biobased Mater. Bioenergy 2016, 10, 219-224. [CrossRef]

6. Chen, G.; Zheng, Z.; Yang, S.; Fang, C.; Zou, X.; Luo, Y. Experimental co-digestion of corn stalk and vermicompost to improve biogas production. Waste Manag. 2010, 30, 1834-1840. [CrossRef] [PubMed]

7. Zhong, W.; Zhang, Z.; Luo, Y.; Qiao, W.; Xiao, M.; Zhang, M. Biogas productivity by co-digesting taihu blue algae with corn straw as an external carbon source. Bioresour. Technol. 2012, 114, 281-286. [CrossRef] [PubMed]

8. Jiang, T.T.; Wang, B.H.; Han, H.J. Analysis and Progress in Treatment of Furfural Wastewater. Liaoning Chem. Ind. 2010, 39, 862-865.

9. Wang, F.; Xuan, C.; Ma, Y.; Sun, Y.; Wu, Q. Products and mechanism of corn stalk after depolymerization with acid. J. Chin. Cereals Oils Assoc. 2015, 30, 1-5.

10. Xu, Z.; Li, W.; Du, Z.; Wu, H.; Jameel, H.; Chang, H.M. Conversion of corn stalk into furfural using a novel heterogeneous strong acid catalyst in $\gamma$-valerolactone. Bioresour. Technol. 2015, 198, 764-771. [CrossRef] [PubMed]

11. Li, Q.; Li, Y.Y.; Qiao, W.; Wang, X.; Takayanagi, K. Sulfate addition as an effective method to improve methane fermentation performance and propionate degradation in thermophilic anaerobic co-digestion of coffee grounds, milk and waste activated sludge with anmbr. Bioresour. Technol. 2015, 185, 308-315. [CrossRef] [PubMed]

12. Chen, Y.; Cheng, J.J.; Creamer, K.S. Inhibition of anaerobic digestion process: A review. Bioresour. Technol. 2008, 99, 4044-4064. [CrossRef] [PubMed]

13. Li, Y.L.; Wang, J.; Yue, Z.B.; Tao, W.; Yang, H.B.; Zhou, Y.F.; Chen, T.H. Simultaneous chemical oxygen demand removal, methane production and heavy metal precipitation in the biological treatment of landfill leachate using acid mine drainage as sulfate resource. J. Biosci. Bioeng. 2017, 124, 71-75. [CrossRef] [PubMed]

14. Ren, N.Q.; Wang, A.J.; Zhao, Y.G. Ecology of Sulfate-Reducing Bacteria in Anaerobic Biotreatment Processes; SciencePress: Beijing, China, 2009; pp. 132-133.

15. Barton, L.L. Sulfate-Reducing Bacteria; Plenum Press: London, UK; Springer: New York, NY, USA, 1995; pp. 150-180.

16. Zhou, X.F.; Ren, N.Q. Acid resistance of methanogenic bacteria in two-Stage anaerobic process treating high concentration methanol waste water. Acta Sci. Circumst. 2004, 24, 633-636.

17. Preez, L.A.D.; Odendaal, J.P.; Maree, J.P.; Ponsonby, M. Biological removal of sulphate from industrial effluents using producer gas as energy source. Environ. Technol. Lett. 1992, 13, 875-882. [CrossRef]

18. Peng, J.W.; Kang, C.L.; Cui, Y.B.; Liu, X.C.; Han, X.K. Application on Wastewater Treatment of Produced Furfural by Free Water Surface Flow Constructed Wetland. J. Jilin Univ. (Earth Sci. Ed.) 2010, 40, 1419-1424.

19. Zou, X.N.; Tan, H.L.; Zhan, B.; He, J.L. Study on Treatment of Furfural Wastewater by Double-effect Evaporation Process. Ind. Saf. Environ. Prot. 2008, 34, 1-4.

20. Qiao, W.; Takayanagi, K.; Shofie, M.; Niu, Q.; Yu, H.Q.; Li, Y.Y. Thermophilic anaerobic digestion of coffee grounds with and without waste activated sludge as co-substrate using a submerged AnMBR: System amendments and membrane performance. Bioresour. Technol. 2013, 150, 249-258. [CrossRef] [PubMed]

21. Vela, F.J.; Zaiat, M.; Foresti, E. Influence of the COD to sulphate ratio on theanaerobic organic matter degradation kinetics. Water SA 2002, 28, 213-216. [CrossRef]

22. Speece, R.E. Anaerobic biotechnology for industrial wastewater treatment. Environ. Sci. Technol. 1983, 17, 416-427. [CrossRef] [PubMed]

23. Ward, D.M.; Olson, G.J. Terminal processes in the anaerobic degradation of an algal-bacterial mat in a high-sulfate hot spring. Appl. Environ. Microbiol. 1980, 40, 67-74. [PubMed]

24. Li, Y.Y.; Lam, S.; Fang, H.H.P. Interactions between methanogenic, sulfatereducing and syntrophic acetogenic bacteria in the anaerobic degradation of benzoate. Water Res. 1996, 30, 1555-1562. [CrossRef]

25. Muyzer, G.; Stams, A. The ecology and biotechnology of sulphate-reducing bacteria. Rev. Microbiol. 2008, 6, 441-454. [CrossRef] [PubMed]

26. Gevertz, D.; Telang, A.J.; Voordouw, G.; Jenneman, G.E. Isolation and Characterization of Strains CVO and FWKOB, Two Novel Nitrate-Reducing, Sulfide-Oxidizing Bacteria Isolated from Oil Field Brine. Appl. Environ. Microbiol. 2000, 66, 2491-2501. [CrossRef] [PubMed] 
27. Beristain-Cardoso, R.; Texier, A.C.; Alpuche-Solís, A.; Gómez, J.; Razo-Flores, E. Phenol and sulfide oxidation in a denitrifying biofilm reactor and its microbial community analysis. Process Biochem. 2009, 44, $23-28$. [CrossRef]

28. Haveman, S.A.; Greene, E.A.; Stilwell, C.P.; Voordouw, J.K.; Voordouw, G. Physiological and gene expression analysis of inhibition of desulfovibrio vulgaris hildenborough by nitrite. J. Bacteriol. 2004, 186, 7944-7950. [CrossRef] [PubMed]

29. Gao, S.; Zhao, M.; Chen, Y.; Yu, M.; Ruan, W. Tolerance response to in situ ammonia stress in a pilot-scale anaerobic digestion reactor for alleviating ammonia inhibition. Bioresour. Technol. 2015, 198, 372-379. [CrossRef] [PubMed]

30. Demirel, B.; Scherer, P. The roles of acetotrophic and hydrogenotrophic methanogens during anaerobic conversion of biomass to methane: a review. Rev. Environ. Sci. Biotechnol. 2008, 7, 173-190. [CrossRef]

31. Riviere, D.; Desvignes, V.; Pelletier, E.; Chaussonnerie, S.; Guermazi, S.; Weissenbach, J.; Li, T.; Camacho, P.; Sghir, A. Towards the definition of a core of microorganisms involved in anaerobic digestion of sludge. ISME J. 2009, 3, 700-714. [CrossRef] [PubMed]

32. Sieber, J.R.; Mcinerney, M.J.; Gunsalus, R.P. Genomic insights into syntrophy: The paradigm for anaerobic metabolic cooperation. Annu. Rev. Microbiol. 2012, 66, 429-452. [CrossRef] [PubMed]

33. Gao, Y.M.; Kong, X.Y.; Xing, T.; Sun, Y.M.; Zhang, Y.; Luo, X.J.; Sun, Y. Digestion performance and microbial metabolic mechanism in thermophilic and mesophilic anaerobic digesters exposed to elevated loadings of organic fraction of municipal solid waste. Energies 2018, 11, 952. [CrossRef]

34. Kindaichi, T.; Ito, T.; Okabe, S. Ecophysiological interaction between nitrifying bacteria and heterotrophic bacteria in autotrophic nitrifying biofilms as determined by microautoradiography-fluorescence in situ hybridization. Appl. Environ. Microbiol. 2004, 70, 1641-1650. [CrossRef] [PubMed]

35. Moran, J.J.; House, C.H.; Freeman, K.H.; Ferry, J.G. Trace methane oxidation studied in several euryarchaeota under diverse conditions. Archaea 2005, 1, 303. [CrossRef] [PubMed]

36. Kern, T.; Linge, M.; Rother, M. Methanobacterium aggregans sp nov., a hydrogenotrophic methanogenic archaeon isolated from an anaerobic digester. Int. J. Syst. Evol. Microbiol. 2015, 65, 1975-1980. [CrossRef] [PubMed]

37. De Lucena, R.M.; Gavazza, S.; Florencio, L.; Kato, M.T.; De Morais, M.A. Study of the microbial diversity in a full-scale UASB reactor treating domestic wastewater. World J. Microbiol. Biotechnol. 2011, 27, $2893-2902$. [CrossRef]

38. Kodama, Y.; Watanabe, K. Isolation and characterization of a sulfur-oxidizing chemolithotroph growing on crude oil under anaerobic conditions. Appl. Environ. Microbiol. 2003, 69, 107-112. [CrossRef] [PubMed]

39. Claudia, G.; Alberto, O.; Claudio, G.; Selene, M.; Fernando, B.; Paola, B. Enhanced sulfate reduction and trichloroethylene (TCE) biodegradation in a UASB reactor operated with a sludge developed from hydrothermal vents sediments: process and microbial ecology. Int. Biodeterior. Biodegrad. 2014, 94, $182-191$.

40. Wu, S.J.; Dang, Y.; Qiu, B.; Liu, Z.; Sun, D.Z. Effective treatment of fermentation wastewater containing high concentration of sulfate by two-stage expanded granular sludge bed reactors. Int. Biodeterior. Biodegrad. 2015, 104, 15-20. [CrossRef]

41. Kiyuna, L.S.; Fuess, L.T.; Zaiat, M. Unraveling the influence of the COD/sulfate ratio on organic matter removal and methane production from the biodigestion of sugarcane vinasse. Bioresour. Technol. 2017, 232, 103-112. [CrossRef] [PubMed]

42. Zhang, H.; Luo, L.; Li, W.; Wang, X.; Sun, Y.; Sun, Y. Optimization of mixing ratio of ammoniated rice straw and food waste co-digestion and impact of trace element supplementation on biogas production. J. Mater. Cycles Waste Manag. 2017, 2,1-9. [CrossRef]

(C) 2018 by the authors. Licensee MDPI, Basel, Switzerland. This article is an open access article distributed under the terms and conditions of the Creative Commons Attribution (CC BY) license (http:// creativecommons.org/licenses/by/4.0/). 